\title{
Measurement of Growth Rates of Streptomycetes: Comparison of Turbidimetric and Gravimetric Techniques
}

\author{
By T. H. FLOWERS AND S. T. WILLIAMS \\ Department of Botany, University of Liverpool, Liverpool L69 $3_{B} B$ \\ (Received I I June 1976; revised 3I August 1976) \\ INTRODUCTION
}

Growth rates of unicellular microbes are usually determined by measurements of culture turbidity or by cell counts. However, growth of filamentous microbes cannot be assessed by counting and the heterogeneous distribution of mycelium generally precludes accurate turbidimetric measurements. Therefore gravimetric determinations, which are laborious and less accurate at low concentration, are required. This partly explains the comparative lack of information on the growth kinetics of such microbes.

The growth kinetics of several fungi grown in submerged culture and on agar media have been studied by Trinci (1969, I97 I $a, b$, I972), who compared specific growth rates, radial extension of colonies and germ-tube growth rates. Most actinomycetes form stable filaments and are generally regarded as slow-growing microbes, but there have been few attempts to determine their growth rates accurately. Haines (1932) recorded exponential germ-tube extension rates of several unidentified isolates, while Marshall \& Alexander (1960) claimed that the rate of increase of mass of a Streptomyces sp. and a Nocardia sp. in submerged culture fitted a cube root relationship. Recently, Schuhmann \& Berger (1976) studied the growth kinetics of Streptomyces hygroscopicus on solid medium.

Since turbidity measurements can be used to estimate growth rates of fungi which have reasonably dispersed growth in submerged culture (Trinci, 1972; Caldwell \& Trinci, 1973), we decided to evaluate the use of turbidimetric methods for determining the specific growth rates of streptomycetes.

\section{METHODS}

A preliminary study of the growth form of neutrophilic and acidophilic streptomycetes in several media was made. A medium supporting good, dispersed growth was selected. This was prepared and sterilized in four parts to prevent precipitation: (i) glucose, $1 \cdot 0 \%$; (ii) $\mathrm{K}_{2} \mathrm{HPO}_{4}, 0.35 \%$; (iii) $\mathrm{MgSO}_{4} .7 \mathrm{H}_{2} \mathrm{O}, 0.05 \% ; \mathrm{NaCl}, 0.05 \%$; (iv) vitamin-free Casamino acids (Difco), 0.I \%; yeast extract (Difco), $0 . \mathrm{I} \% ; \mathrm{FeSO}_{4} .7 \mathrm{H}_{2} \mathrm{O}, 0.00 \mathrm{I} \%$; citric acid, $0.00 \mathrm{I} \%$; L-proline or L-asparagine, $0.1 \%$. The concentrations given are the final ones in the medium after mixing the parts. For optimum growth of neutrophilic strains, the medium contained L-asparagine (GCA) and the $\mathrm{pH}$ was adjusted to $7 \cdot 0$. Acidophiles were grown with L-proline (GCP) at $\mathrm{pH} 4.0$.

A preliminary survey of the growth form of 22 neutrophilic and 22 acidophilic soil isolates was carried out. These were grown in $40 \mathrm{ml} \mathrm{GCA}$ or GCP medium in $250 \mathrm{ml}$ conical flasks at $30{ }^{\circ} \mathrm{C}$ in an orbital incubator rotating at $250 \mathrm{rev}$. $\mathrm{min}^{-1}$. The amount and form of growth was assessed by microscopic examination after $48 \mathrm{~h}$.

Twelve strains grew in a reasonably dispersed form and from these two neutrophiles (F6 and FI3) and two acidophiles (MRI2 and SWI) were selected for detailed study. Six others 
were used solely for turbidimetric determinations of growth rates. Both of the selected neutrophiles were isolated from a pine forest sand $(\mathrm{pH} 7 \cdot 5)$ at Freshfield, Merseyside. The acidophile MRI2 was isolated from open cast coal mine spoil ( $\mathrm{pH} 4.5)$ at Wisconsin, U.S.A., and swi from sand under Calluna vulgaris $\left(\mathrm{pH}_{3} .5\right)$ at Thurstaston, Merseyside.

GCA and GCP media were dispersed in $40 \mathrm{ml}$ volumes into $250 \mathrm{ml}$ conical flasks, each of which had a $20 \mathrm{ml}$ test tube of $15 \mathrm{~mm}$ diameter fused to its side. Similar flasks were used by Trinci (1972). Inoculum of the selected strains was prepared by removing spores from plate cultures on oatmeal agar ( $\mathrm{pH} 4.5$ or 7.0 ) and placing them into vials containing $2.5 \mathrm{ml}$ sterile water with a few glass beads. These were shaken vigorously for $5 \mathrm{~min}$ and the volume was then made up to Io ml. Flasks were inoculated with $0.05 \mathrm{ml}$ suspension, giving about $10^{5}$ spores per $\mathrm{ml}$ of medium. Use of a more dilute spore suspension or actively growing mycelium led to pellet formation on incubation.

Readings of the turbidity in inoculated flasks were taken hourly. The culture was shaken and the side tube was filled by carefully tipping the flask, avoiding formation of air bubbles. The tube was then placed in an EEL nephelometer head and the reading on the previously standardized galvanometer was noted. Five replicate readings were taken for each flask culture.

Gravimetric determinations were made to calibrate nephelometer readings against dry weight of cells for each strain. They were also used for direct determinations of growth rates for comparison with those obtained from turbidimetric measurements. The mycelium in a flask was harvested by filtration through a tared filter (Sartorius; cellulose nitrate; pore size $0.2 \mu \mathrm{m}$ ), and then washed with deionized water and dried at $105{ }^{\circ} \mathrm{C}$ to constant weight.

Turbidity measurements were converted to dry weight values using the calibration curve and plotted as $\log _{e}$ dry weight against time. The best fit lines were determined by regression analysis for the linear part of each curve and the specific growth rate and doubling time were calculated. Direct determinations of dry weight were treated similarly.

Samples were taken from cultures at intervals during the exponential and stationary growth phases. Hyphae were sedimented by centrifuging, washed in deionized water and fixed in $10 \%(\mathrm{w} / \mathrm{v})$ buffered formalin $(\mathrm{pH} 7 \cdot 2)$ for $24 \mathrm{~h}$. They were then washed twice with deionized water and air dried on coverslips. The coverslips were fixed to metal specimen stubs, coated under vacuum with gold-palladium and examined with a Stereoscan electron microscope (Cambridge Scientific Instruments Ltd, Cambridge) at $20 \mathrm{kV}$.

\section{RESULTS}

A linear relationship between turbidity and dry weight was obtained for all four strains, up to a hyphal density of about $0.4 \mathrm{mg} \mathrm{m}^{-1}$ (Fig. I). The relationship for the two neutrophiles (F6 and FI3) ceased to be linear above this point due to production of small amounts of soluble brown pigment during the later stages of growth.

Replication of nephelometer readings taken from one flask at a given time was good. There was some variation between flasks due to differences in the length of the lag phase, but growth rates calculated from replicate flask cultures were very similar. Specific growth rates calculated from gravimetric measurements were slightly lower and more variable than those from turbidimetric measurements (Table I). Rates for neutrophiles were generally a little higher than those for acidophiles.

During exponential growth, all four strains formed small aggregates consisting of a loose network of hyphae (Fig. 2a). Aggregates of SWI were denser than the others and MRI2 also 


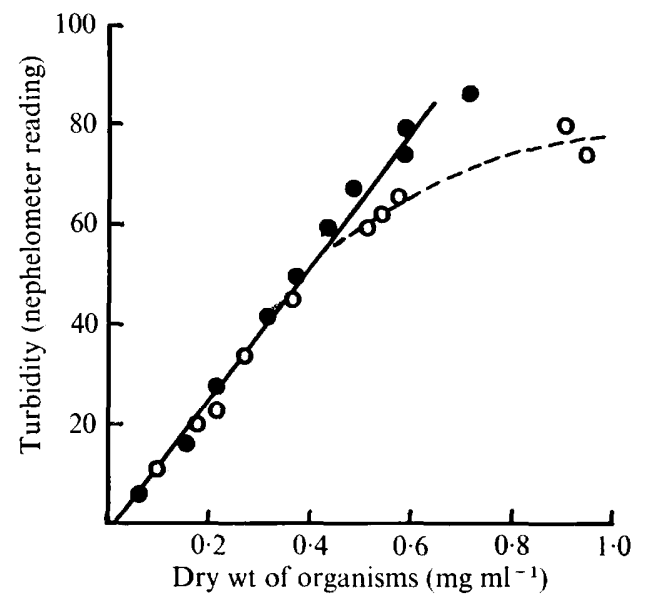

Fig. I. Relationship between culture turbidity and dry weight of hyphae for neutrophile ( $\bigcirc)$ and acidophile (O) streptomycetes.
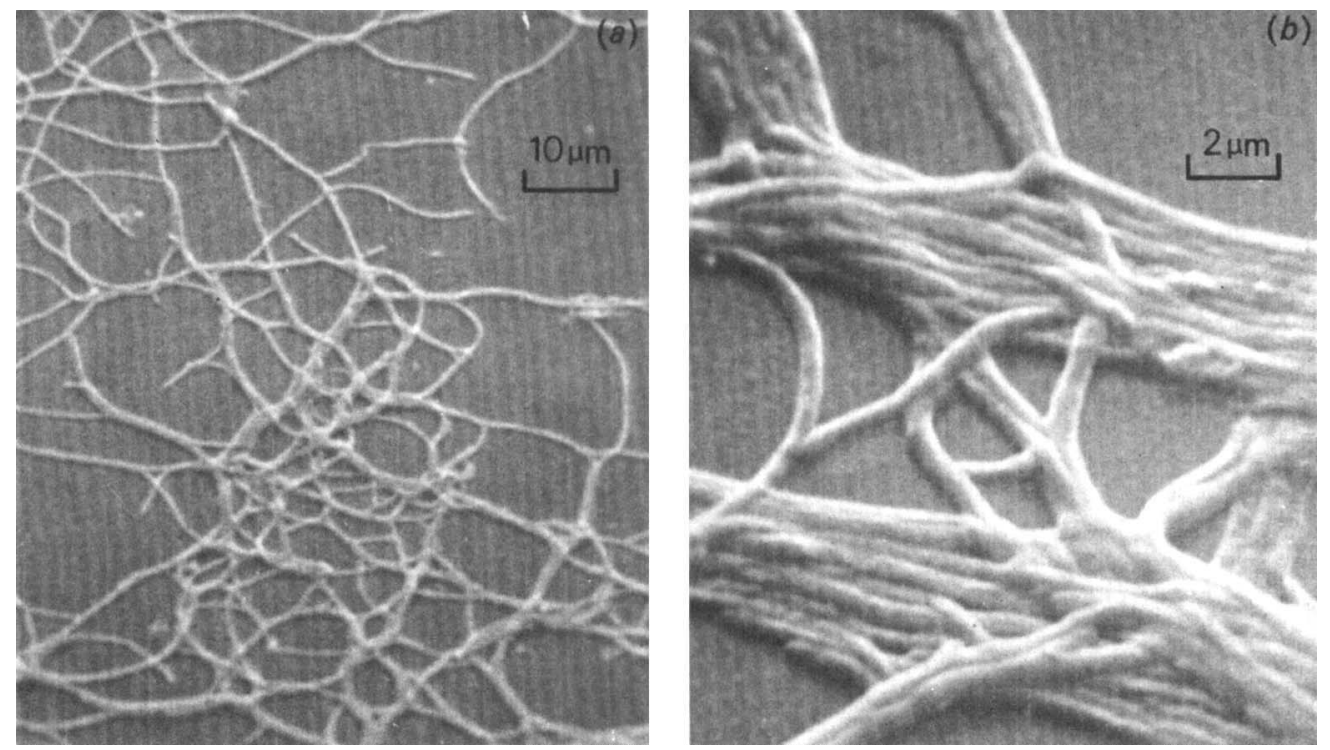

Fig. 2. Growth forms of streptomycete $\mathbf{F} 6$ during $(a)$ the exponential phase, $(b)$ the stationary phase. Scanning electron micrographs.

formed many short lengths of hyphae, probably by fragmentation. In the stationary phase, all strains formed hyphal ropes (Fig. $2 b$ ).

\section{DISCUSSION}

The results show that the growth rates of filamentous actinomycetes can be determined accurately from turbidity measurements, despite theoretical objections (Calam, I969) to the use of such methods. It is necessary to ensure that reasonably dispersed growth occurs by selecting an appropriate medium, culture conditions and inoculum size. The comparative 
Table I. Growth rates of streptomycetes determined by turbidimetric and gravimetric measurements

\begin{tabular}{|c|c|c|c|c|}
\hline \multirow[b]{2}{*}{ Strains } & \multicolumn{2}{|c|}{ Specific growth rate $\left(\mathrm{h}^{-1}\right)$} & \multicolumn{2}{|c|}{ Doubling time $(\mathrm{h})$} \\
\hline & Turbidimetric & Gravimetric & Turbidimetric & Gravimetric \\
\hline \multicolumn{5}{|c|}{$\begin{array}{l}\text { Neutrophiles } \\
\left(\mathrm{pH} 7 \cdot 0,30^{\circ} \mathrm{C}\right)\end{array}$} \\
\hline F6 & $0.642 \pm 0.011$ & $0.610 \pm 0.333$ & I.08 & $I \cdot I 4$ \\
\hline FI 3 & $0.596 \pm 0.008$ & $0.583 \pm 0.066$ & $I \cdot 16$ & $1 \cdot 19$ \\
\hline F9 & $0.530 \pm 0.005$ & . & $\mathbf{I} \cdot 3 \mathbf{I}$ & $\cdot$ \\
\hline M9 & $0.620 \pm 0.007$ & . & $1 \cdot 12$ & . \\
\hline FI5 & $0.556 \pm 0.014$ & . & $\mathrm{r} \cdot 25$ & . \\
\hline \multicolumn{5}{|c|}{$\begin{array}{l}\text { Acidophiles } \\
\left(\mathrm{pH} 4{ }^{\circ} \mathrm{O}, 30^{\circ} \mathrm{C}\right)\end{array}$} \\
\hline MRI 2 & $0.525 \pm 0.005$ & $0.494 \pm 0.034$ & $1 \cdot 32$ & $I \cdot 40$ \\
\hline SWI & $0.414 \pm 0.009$ & $0.368 \pm 0.057$ & $I \cdot 68$ & I $\cdot 88$ \\
\hline H & $0.371 \pm 0.004$ & . & $\mathrm{I} \cdot 87$ & - \\
\hline SI5 & $0.249 \pm 0.005$ & . & $2 \cdot 79$ & . \\
\hline sw2 & $0.485 \pm 0.009$ & . & $I \cdot 43$ & . \\
\hline
\end{tabular}

convenience of turbidity measurements facilitates large numbers of determinations of hyphal mass.

Our results are similar to those of Trinci (1972) and Caldwell \& Trinci (1973) who showed that turbidity measurements could be successfully used for determining the growth rates of some fungi. The doubling time of Geotrichum candidum, determined gravimetrically, was $2.0 \mathrm{~h}$ (Trinci $197 \mathrm{I} b$ ), compared with $\mathrm{I} \cdot 7 \mathrm{~h}$ when determined by turbidity measurements (Trinci, 1972). A similar difference between growth rates determined by gravimetric and turbidimetric measurements was noted here.

There is little previous information on the growth rates of actinomycetes with stable hyphae. Haines (1932) obtained values of $0.248 \mathrm{~h}^{-1}$ to $0.576 \mathrm{~h}^{-1}$ by measuring germ-tube extension rates, but the validity of this approach is questionable as the germ-tube specific growth rates of fungi are greater than those calculated from gravimetric measurements of growth in submerged culture (Trinci, I97 $\mathrm{r}$ a). Schuhmann \& Berger (1976) noted that germ tubes of Streptomyces hygroscopicus had a much higher growth rate than that of mycelium. Specific growth rates of a number of filamentous fungi have been determined by gravimetric methods (Trinci, I97I $b, 1972$ ). Values ranged from $0.102 \mathrm{~h}^{-1}$ (Mucor racemosus at $25^{\circ} \mathrm{C}$ ) to $0.6 \mathrm{IO} \mathrm{h}^{-1}$ (Geotrichum candidum at $30^{\circ} \mathrm{C}$ ). The latter is probably the highest fungal growth rate recorded (Trinci, 1972). Values recorded for some of the streptomycetes studied exceeded this and the growth rates were generally higher than those reported for fungi.

Further accurate determinations of the growth rates of other actinomycetes and the effect of culture conditions upon them are now needed.

A research grant from Eli Lilly and Co. is gratefully acknowledged. 


\section{REFERENCES}

CALAM, C. T. (1969). The culture of micro-organisms in liquid medium. Methods in Microbiology $\mathbf{1}, 255-326$.

CAldwell, I. Y. \& Trinci, A. P. J. (1973). The growth unit of the mould Geotrichum candidum. Archiv für Mikrobiologie 88, I-10.

HaINES, R. B. (I932). The influence of temperature on the rate of growth of saprophytic actinomycetes. Journal of Experimental Biology 9, 45-60.

MARShall, K. C. \& ALEXANDER, M. (I960). Growth characteristics of fungi and actinomycetes. Journal of Bacteriology 80, 41 2-4I6.

SCHUHMANN, E. \& BERGER, F. (1976). Mikroskopische Untersuchungen zur Wachstumskinetick von Streptomyces hygroscopicus. Zeitschrift für allgemeine Mikrobiologie 16, $20 \mathrm{I}-2 \mathrm{I} 5$.

Trinci, A. P. J. (1969). A kinetic study of the growth of Aspergillus nidulans and other fungi. Journal of General Microbiology 57, $11-24$.

Trinci, A. P. J. (1971 $a$ ). Experimental growth of the germ tubes of fungal spores. Journal of General Microbiology $67,345-348$.

Trinci, A. P. J. (197I $b$ ). Influence of the peripheral growth zone on the radial growth rate of fungal colonies. Journal of General Microbiology 67, 325-344.

TrINCI, A. P. J. (1972). Culture turbidity as a measure of mould growth. Transactions of the British Mycological Society 58, 467-473. 